This is the final peer-reviewed accepted manuscript of:

Valeria Vignali, Arianna Bichicchi, Andrea Simone, Claudio Lantieri, Giulio Dondi, Marco Costa, Road sign vision and driver behaviour in work zones, Transportation Research Part F: Traffic Psychology and Behaviour, Volume 60, 2019, Pages 474-484, ISSN 1369-8478

The final published version is available online at:

https://doi.org/10.1016/j.trf.2018.11.005

Rights / License:

The terms and conditions for the reuse of this version of the manuscript are specified in the publishing policy. For all terms of use and more information see the publisher's website.

This item was downloaded from IRIS Università di Bologna (https://cris.unibo.it/)

When citing, please refer to the published version. 


\title{
ROAD SIGN VISION AND DRIVER BEHAVIOR IN WORK ZONES
}

\author{
AUTHORS \\ Valeria Vignali ${ }^{1}$, Arianna Bichicchi ${ }^{1}$, Andrea Simone ${ }^{1}$, Claudio Lantieri ${ }^{1}$, Giulio Dondi ${ }^{1}$, Marco Costa ${ }^{2}$ \\ ${ }^{1}$ Department of Civil, Chemical, Environmental and Material Engineering, University of Bologna, Italy \\ 2 Department of Psychology, University of Bologna, Italy
}

\section{ABSTRACT}

The effectiveness of roadwork signs on drivers' safety is a poorly investigated topic. The present study examined visual fixations of 29 participants to work zone signs, while driving 27 $\mathrm{km}$ along rural roads. The drivers' visual fixations on the work zones signs were recorded with an eye tracking device, synchronized to a GPS recorder that collected kinematic data. The routes crossed 23 roadwork zones, including a total of 69 vertical work zone signs. Visual behaviour to roadwork signs were compared to visual behaviour to permanent vertical signs. The results revealed that drivers glanced at both temporary and permanent signs along the roadwork areas with a similar $40 \%$ frequency. In addition, they glanced at single roadwork signs more often and for longer than at multiple-roadwork signs. The main findings of this paper lead to conclude that driver behaviour, investigated by comparing instant speed and visual fixations, is frequently unsafe.

\section{KEYWORDS}

Roadwork signs, Roadwork zones, Vertical road signs, Driver perception, Eye tracker, Speed, Fixations.

\section{INTRODUCTION}

\subsection{Safety in roadwork zones}

Roadwork zones are unsafe locations, as they disrupt the drivers' expectations about the road geometry, meaning that they have to make sudden adjustments to their driving speed. Recent research seems to agree that the presence of work zones is likely to increase the crash rate (Yang, Ozturk, Ozbay, \& Xie, 2015).

Because of ageing roads, maintenance work is becoming ever more common, so that it is possible to affirm that accidents at roadwork sites are likely to increase and, for this reason, countermeasures should be taken to prevent them.

The overall knowledge about work zone safety was mainly referred to main roadways (such as highways and motorways) and major worksites (those that in general relate to standardizing road layouts). There is little research that addressed safety issues in roadworks in rural roads 
that are simpler, smaller in size and generally short-termed. Despite that, even rural road crashes may have a considerable social and economic cost.

An extensive literature who analyses work zone collisions mostly rely on simple approaches, such as investigating crashes frequency, external factors, characteristics of the work zones and the type of crash. Observational studies that compared crash rate before and during roadworks have been carried out to test the safety level at specific roadway maintenance sites, by assessing the increase in crash frequency caused by roadworks. Khattak, Khattak, \& Council (2002) examined the combined effect of increasing length and duration of freeway worksites in California, finding that there was a significant increase in crash rate compared to the baseline. According to the USA Transportation Research Board (TRB), the occurrence of rear-end and fixed-object collisions increases in correspondence with work zones (Campbell et al., 2012). Similarly, recent data on Italian roads indicate that, between 2007 and 2012, there were 762 collisions in roadwork zones (with 21 fatalities and 1,252 injuries). Rear-end collisions were the most frequent, followed by single-vehicle accidents and lateral crashes caused by the driver changing lane (La Torre, Domenichini, \& Nocentini, 2017). Besides crash frequency, crash severity in roadwork areas was also investigated. A recent study revealed that advanced-warning, activity and termination areas of a work zone were all associated with higher injury severity crashes (Osman, Paleti, \& Mishra, 2018).

Other investigations have similarly developed methodologies to predict crash frequency (Crash Prediction Model), adapting the general equations of the Crash Modification Factor (CMF) to roadworks. CMF is a multiplicative factor that computes the expected number and severity of crashes after implementing a given countermeasure at a specific site (AASHTO - American Association of State Highway and Transportation, 2010). Different methodologies and CMF formulations were developed to estimate the expected number of crashes through the use of prediction model weight (Gross, Persaud, \& Lyon, 2010). Crash severity relating to work-inprogress zones is connected to different factors, as the vehicle speed or the involvement of road workers. On this latter point, Kröyer, Jonsson, \& Várhelyi (2014) found that at increasing speed there is a significant increase in fatal collisions involging pedestrians. More precisely, they found that the risk of fatality in collisions between a car and a pedestrian is 4 to 5 times higher at $50 \mathrm{~km} / \mathrm{h}$ than at $30 \mathrm{~km} / \mathrm{h}$. Therefore, forewarn drivers about the presence of working areas represent the simpler practice to induce a speed reduction.

However, speed limits are frequently ignored on road sections with hazardous conditions, such as when there is work-in-progress. Bella (2009), for example, simulated a crossover work zone, with the outcome that mean speed was below the limit only when drivers faced physical constraints. It seems that drivers make adjustments to their driving speed in reaction to contextual changes in the road, rather than simply in compliance with the road sign content. This means that drivers are more likely to comply with speed limits if they see that they match 
a concomitant danger, as workers or police on the road (Blackman, Debnath, \& Haworth, 2014a). The drivers' average speed decreased only if they perceive the necessity to do so (Finley, Jenkins, \& McAvoy, 2015). A similar study also examined the drivers' subjective evaluation about whether work zone features had any influence over their choice of speed. The feature that was evaluated as most effective was workers activity, police presence and speed feedback displays (Blackman, Debnath, \& Haworth, 2014b).

A main factor in determining whether a crash will occur is linked to whether a work zone is easily visible and recognized. Temporary road signs are the most common tools to achieve both work zone conspicuity and legibility (Bella, 2009), because they inform drivers about the oncoming road conditions beforehand. The effectiveness of signage is related to the "priming effect", the ergonomic paradigm consisting in the anticipation of some information (stimulus) that would influence the response to a subsequent stimulus. In this field, the presence of warning signs informs the driver about the upcoming worksites and get him ready to take the appropriate action before reaching the hazard. Several studies have proved that being warned beforehand about something enables people to react more quickly, inducing a more correct driving behaviour (Charlton, 2006; Crundall \& Underwood, 2001). The capacity to respond to the sign is however influenced by the experience of the context and by the overall driving expertise.

Some studies support the theory that even unconsciously perceived signs (i.e., that drivers do not recall later) are effective in terms of reducing speed, as they implicitly warn drivers about hazards, inducing them to exert proper control over their vehicles (Fisher, 1992; Summala \& Hietamaki, 1984).

\subsection{Readability of roadwork signs}

Both temporary and permanent signage cover an important role in the passive protection of vehicles, passengers, workers and site equipment, since they are used to signal work zones. According to this, it is fundamental to consider their capacity to be easily readable.

Firstly, several studies supports the importance of visual graphics in signage equipment (Costa et al., 2014; Ullman, Trout, \& Dudek, 2009; Ullman \& Brewer, 2014) and, moreover, the European Union has set up standards for vertical road signs, including graphics such as shape, background colour, border colour, size and symbols (Vienna Convention on Road Signs and Signals, 1968).

Literature offers several studies investigating the role of sign visibility and legibility in relation to the sight distance (Costa et al., 2014; Discetti \& Lamberti, 2011; Zwahlen, 1995), but none of them evaluated specifically temporary signage.

Regarding sign design (graphic content, positioning and orientation) Lewis (1989) made a great effort in highlighting the importance of a standardization in work zone signs positioning, 
also in terms of terminology and definitions. A correct positioning, in fact, means that the road can be more easily monitored, which in turn can avoid the problem of not being warned about the potential negative side-effects of the roadworks, which can include traffic jams, which are a major factor in the increased risk of crashes (Beijer, Smiley, \& Eizenman, 2004). In addition, a recent study regarding sign positioning, confirmed that it plays a key role as it affected the drivers' perception-response time and speed (Discetti \& Lamberti, 2011). A correct positioning practice, also, suggests to avoid sign overcrowding, as 'visual pollution' from roadside information (intended as billboards, warnings and installations) can distract drivers (Edquist, Horberry, Hosking, \& Johnston, 2011) or let drivers to lose important information (Liu, 2005). Besides, the content of roadwork signs is supposedly to be crucial for the comprehension of drivers' reaction. Several ergonomics studies, in fact, confirm that sign effectiveness does not depend solely on the readability, invoking thus the credibility principle. A study measuring vehicle speed in the presence of different signs found that drivers lift their foot from the accelerator more often and more pointedly when they saw signs they considered to be significant (Summala \& Hietamaki, 1984).

\subsection{Roadwork activity}

A relevant factor for the investigation of drivers' behaviour at work zones is the conspicuity of roadworks, by which we mean the visibility of site operations, workers and active vehicles. Visible site activity, in fact, seems to be an essential requirement on speed modulation. According to the results of a recent study (Steinbakk, Ulleberg, Sagberg, \& Fostervold, 2017), higher speed was preferred at work zones without visible roadwork activity and roadwork activity was the strongest predictor of preferred speed. An interesting study by Benekohal and Wang (1994), involving more than one hundred drivers, computed the actual speeds that drivers were travelling at when reaching a road site where work-in-progress was clearly indicated, informing them that they were approaching an operational work site. The findings revealed that the drivers' speed adjustment was strictly connected to their initial speed. Also, it was noted that all the drivers, including those speeding, generally reduced their speed and continued to do so while transiting through the work zone. "Extremely" speedy drivers represented an exception, slowing down in the advance-warning area and speeding up immediately after passing it.

Similarly, the drivers' choices of speed were investigated in presence or absence of road workers. Here, the results show that drivers are significantly more cautious in the presence of workers, as they chose to drive more slowly (Blackman et al., 2014b). Another study confirmed that the size of this effect is dependent on whether the workers are conspicuous. If drivers see solitary or small groups of workers, they are less likely to reduce their speed than if they see larger groups of workers (Haworth, Symmons, \& Mulvhill, 2002). 
128 Eye trackers make possible to investigate the integrated and complex relationship between 129 drivers, traffic, environment and road infrastructure (Bucchi, Sangiorgi, \& Vignali, 2012; Dondi, 130 Simone, Lantieri, \& Vignali, 2011). This technology allows the assessment of fixation events 131 (i.e., when the eyes focus on a specific point of the scene), distinguishing fixations from 132 saccades (i.e., quick movement of the eyes), providing a direct measure of whether signs are glanced. In addition, fixation duration provides important information on the depth of visual processing. Literature offers a vast body of evidence that eye tracking technology could be exploited to determine how road equipment affects drivers (Costa et al., 2014; Costa, Simone, Vignali, Lantieri, \& Palena, 2018; Filtness et al., 2017; Lantieri et al., 2015; Mantuano, Bernardi, \& Rupi, 2017; Taylor et al., 2013; Topolšek, Areh, \& Cvahte, 2016; Zwahlen, 1995), involving both simulated and real driving environments.

Nevertheless, a few eye tracking applications has been carried out to investigate drivers' visual behaviour at work zones. For example, drivers' gazing patterns were monitored in a virtual scenario where there were traffic signs belonging to the maintenance roadwork operation. The eye tracker recordings proved useful in concluding that repeated exposure to signs was beneficial to drivers and that interference between permanent and temporary signs is to be avoided, as the drivers' attention is split between them (De Ceunynck et al., 2015). Another study focused on temporary dynamic message signs, and it found that drivers spent longer on fixing their gaze on signs that warned about the presence of road workers (Rahman, Strawderman, Garrison, Eakin, \& Williams, 2017). As most of the experimental research were conducted in driving simulators, this paper aims to fill the gap analysing drivers' gaze to roadwork signs in a real driving test.

\section{METHODS}

\subsection{Participants}

Twenty-nine participants were recruited among researchers, graduate and undergraduate engineering students. Twenty were men (mean age: 32.95 years, SD: 11.72, range: 19-56) and 9 were women (mean age: 36.1 years, $S D$ : 12.00, range: 22-54). They all held a regular driving license for cars, with a mean driving expertise of 14.39 years (SD: 9.95) and a mean value of kilometres per year of 14,770 (SD: 9,604). Participants had normal vision without glasses or contact lenses, that prevented the recording of eye movements. They were not informed about the true aim of the study, having been told instead that they were testing the use of a mobile eye tracker device during a driving task. At last, their participation was voluntarily. 


\subsection{Experimental settings}

Driving tests were carried out on rural roadways in Northern Italy, throughout the provinces of Bologna and Reggio Emilia. The selected routes typically had high accident rate and many scattered small-sized road maintenance work zones. The road geometry was consistent along the route, and was a single carriageway with two $3.75 \mathrm{~m}$ wide lanes, a shoulder width of $1.5 \mathrm{~m}$ (not always present), and a signalled speed limit of $70 \mathrm{~km} / \mathrm{h}$.

Along the experimental route, drivers encountered 23 small-sized roadwork zones, with no reduction in lane width at either side. Urban roadworks were excluded from the data analysis. In relation to the signs in the work zones, each driver encountered a total of 69 vertical signs, all with static content, belonging to both temporary (yellow background) and permanent (white background) road vertical signs. The signs with a yellow background were mostly warning signs, while the permanent signs were mostly regulatory road signs. Ten of the considered work zones displayed a single sign (roadworks of negligible length), while the remaining 13 work zones displayed multiple signs (more than two, with an average length of the work zone of $152.61 \mathrm{~m}$ ). The single signs were all placed at road level, mounted on tripods with an elevation of $0.6-1.20 \mathrm{~m}$ from the road surface, beyond the edge-line markings. Work zones with more than two signs included both tripod-mounted and pole-mounted signs, the latter with a maximum height of $2.20 \mathrm{~m}$ and placed at $0.3 \div 1 \mathrm{~m}$ from the roadside, in compliance with Italian regulations (Figure 1). Roadwork activity, in terms of presence of visible workers or active vehicles, was encountered in 14 sites over the total of 23 included in the study.
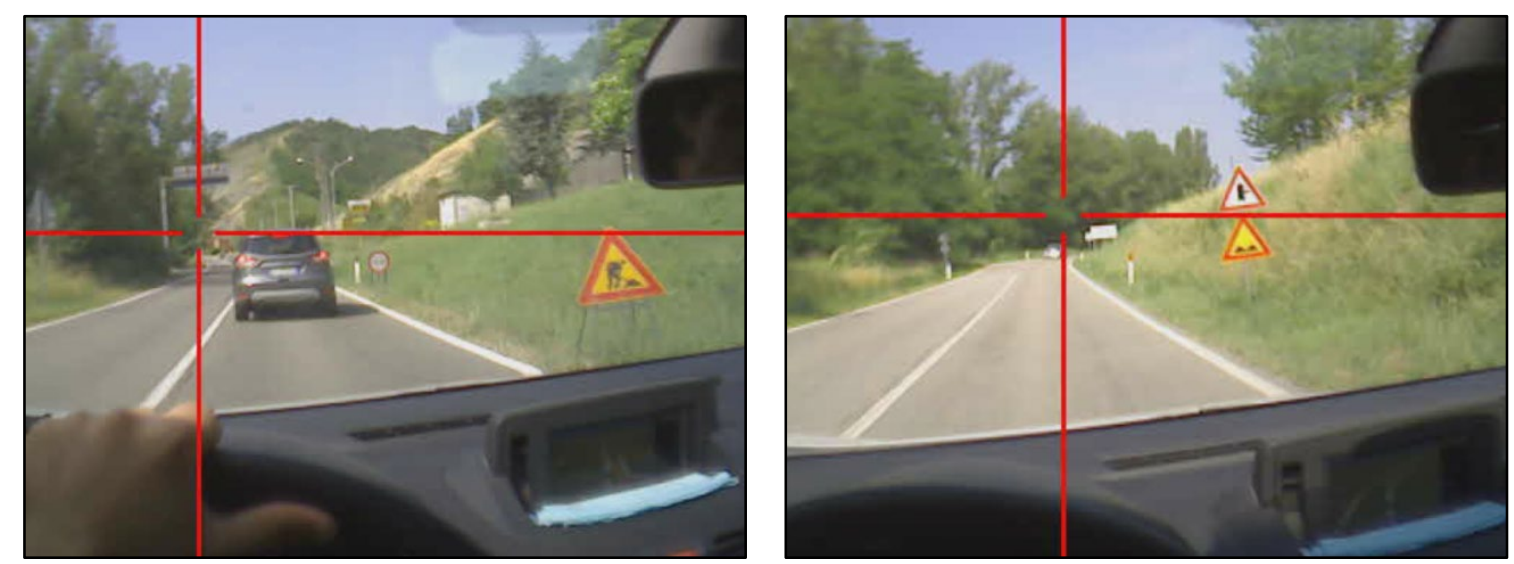

Figure 1: Tripod-mounted temporary sign (left) and pole mounted temporary sign (right). All temporary signs were triangular in shape, with a yellow background and a red border.

\subsection{Apparatus}

Experimental vehicles were a Fiat Panda and a BMW series 1 car. Data was collected from 9.30 to 12.00 and from 14.00 to 16.30 , to avoid peak rush hours. Driving tests were conducted under good weather conditions, with a dry road surface and complete visibility. 
The test vehicles were provided with a Racelogic Video V-Box Pro, a GPS data logger capable of detecting and recording kinematic parameters (forward and lateral acceleration, speed). Two cameras and a GPS antenna, connected with cables to the Video V-Box, were positioned on the top of the cars and recorded the external road scenario, as well as data on acceleration, speed and GPS coordinates. Each driver was given a trial run to get used to the car before starting out along the test route. Speed was recorded with an accuracy of $0.1 \mathrm{~km} / \mathrm{h}$ and distance accuracy was $\pm 50 \mathrm{~cm}$. The recorded data were analysed using Performance Tools software. The eye tracking equipment and the Video V-Box Pro equipment were kept on the back seat of the car and were monitored by one of the experimenters, who was instructed not to talk to the driver except if assistance was requested.

The combined use of eye tracking monitoring and vehicle kinematic data meant allowed an accurate assessment of the driver' behaviour in work zones. Eye-movement data were available for 29 drivers and kinematic data for 28 drivers, due to technical problem to the Video V-Box equipment in one participant.

Eye movements were recorded with an ASL Mobile Eye-XG tracker. Two digital high-resolution cameras were attached to lightweight eyeglasses. One camera recorded the visual scene while the other camera targeted the participant's eye. The eye tracking recordings were only carried out for the driver's right eye and a calibration process was conducted for each participant. The calibration process took place in a parking lot in a stationary car and involved asking the participants to look at a minimum of 15 visual points spread across the whole scene. The calibration points were chosen between the vertexes and the centres of small objects of the driver's visual scene. During the tests, the eye movement sampling rate was $30 \mathrm{~Hz}$ (i.e., $33 \mathrm{~ms}$ time resolution). Spatial accuracy was $0.5-1^{\circ}$. The ASL Mobile Eye-XG software allowed the researchers to match the calibrated datasets with the video recordings and to create, for each participant, a video showing the eye-fixations superimposed to the visual scene (example in Figure 1).

\subsection{Data analysis}

\subsubsection{Personal data}

Personal data (age, driving licence category, years of car driving, kilometres per year, accident history, prior knowledge of the experimental route) were collected at the end of the experiment, after the driving test. Self-evaluation of driving skills was asked to participants according to four levels: "poor", "average", "good" and "excellent". In particular, $24 \%$ of the participants had been responsible of at least one accident and $62 \%$ of them had a prior knowledge of the route selected for this study. 
230 Drivers' eye fixations on the road signs were assessed through a frame-by-frame analysis of 231 the ASL Mobile Eye-XG video output. Drivers were considered to have fixated a work zone 232 sign if the fixation point (the intersection between the horizontal and vertical line in Figure 1) 233 was superimposed over the road sign area (AOI: Area of Interest) for at least two frames (66 $234 \mathrm{~ms}$ ), to avoid the inclusion of saccadic movements. Although research practice normally 235 considers higher temporal thresholds for the definition of a fixation (Holmqvist et al., 2011), the 236 authors' choice was justified by the highly dynamic environment in which eye movements were 237 recorded. Under such conditions, differently from a recording in a virtual environment or in a 238 more controlled setting as in a laboratory, the highly dynamic optical flow of a real driving 239 context implies a rapid sequence of saccades and short fixations (Costa, Simone, et al., 2018). 240 The total fixation duration was computed multiplying $33 \mathrm{~ms}$ by the number of frames in which 241 the road sign was fixated.

242 Once the scorer detected an eye fixation on a work zone sign, the distance of this visual fixation 243 (longitudinal distance on approach to the sign) was acquired by synchronizing the eye tracker 244 video with the Video-V-Box output (Figure 2). The distance between the first fixation to a road 245 sign and the position where the car was perpendicular to the sign (overtaking the sign) was 246 computed using the Video-V-Box distance parameter. In the case of multiple fixations, the 247 distance was computed considering the first fixation. 

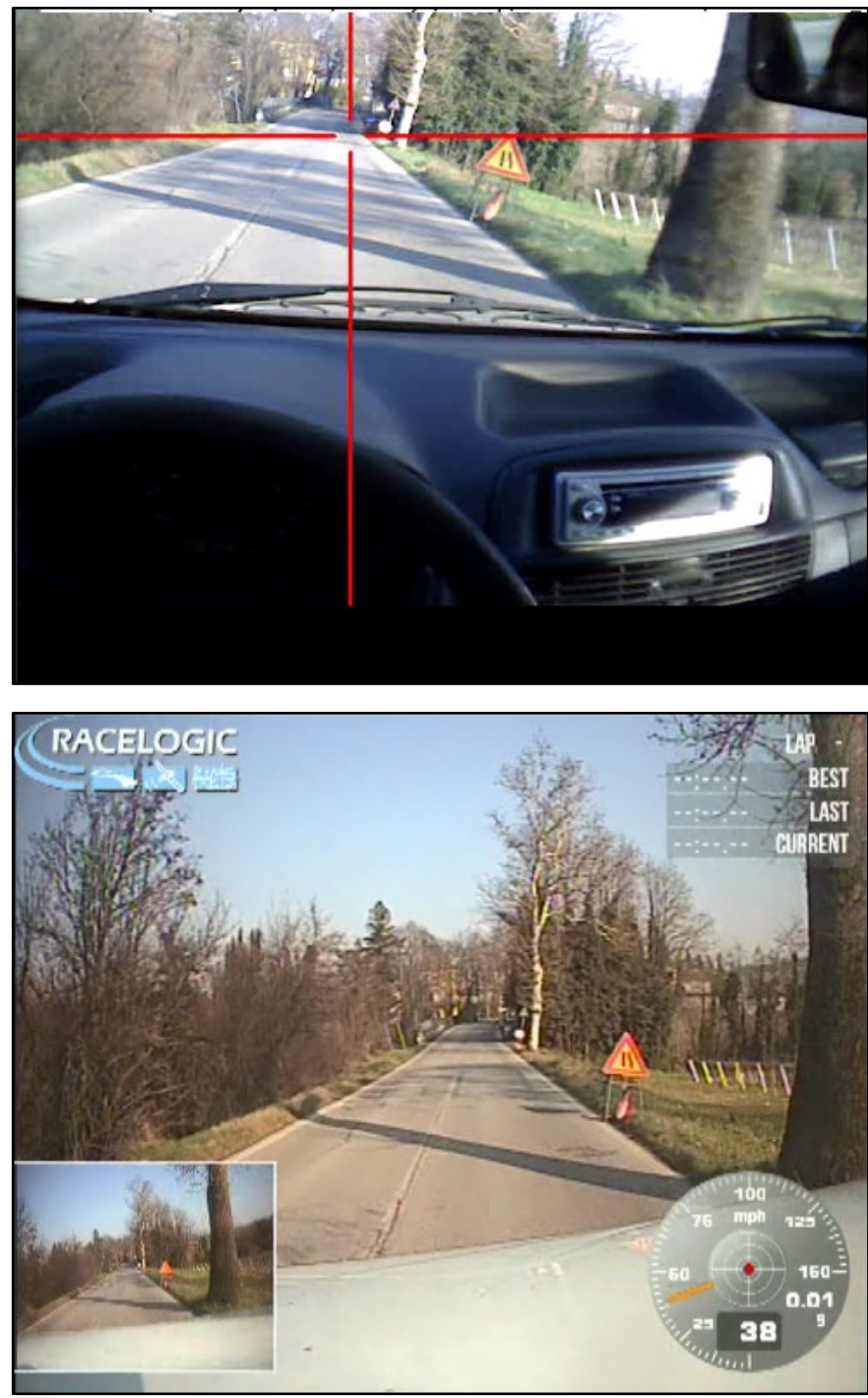

Figure 2: Video V-Box (bottom) and Mobile Eye Tracker (top) synchronization for the computation of the distance of first-fixation to a road sign.

\subsubsection{Speed analysis}

Speed was entered in the analysis considering these parameters:

- instant speed, as the speed at the time of first-fixation to the road sign;

- approaching speed, as the speed at $100 \mathrm{~m}$ before the first sign of the work zone;

\section{RESULTS}

3.1 Road sign fixation rates

Table 1 shows the fixation frequency and the absolute frequency of the road signs included in the work zones considered in the study. 
266 In decreasing order, the road signs that received more glances were: Slippery road (64.2\%), 267 Uneven road (53.85\%), Generic danger (50.41\%), Loose chippings (50\%). The road signs that 268 were glanced with a percentage lower than 50\% were: No overtaking (47.92\%), Roadworks 269 (44.01\%), Keep left (35.17\%), Speed limit (35.17\%), Work zone ahead (37.14\%), Give priority 270 to vehicles from opposite direction (28.57\%), Work zone end (27.78\%), Road narrows (22.5\%),

271 Modified visibility (14.29\%), Hump (0\%).

272

273 Table 1:

274 Fixation frequency and absolute frequency for each road sign included in the work zones.

\begin{tabular}{|c|c|c|c|}
\hline Road sign & Sign icon & \# & Fixation frequency \\
\hline Roadworks & & 17 & $44.01 \%$ \\
\hline Generic Danger & & 9 & $50.41 \%$ \\
\hline Hump & & 2 & $0.00 \%$ \\
\hline Road Narrows & & 3 & $22.50 \%$ \\
\hline Loose Chippings & & 2 & $50.00 \%$ \\
\hline Uneven Road & & 2 & $53.85 \%$ \\
\hline Modified Viability & & 1 & $14.29 \%$ \\
\hline Work Zone Ahead & \begin{tabular}{|c|} 
INIZIO \\
CANTIERE
\end{tabular} & 4 & $37.14 \%$ \\
\hline Work Zone End & & 2 & $27.78 \%$ \\
\hline Slippery Road & & 2 & $64.29 \%$ \\
\hline $\begin{array}{c}\text { Give priority to } \\
\text { vehicles from opposite } \\
\text { direction }\end{array}$ & & 2 & $28.57 \%$ \\
\hline Speed Limit & & 12 & $35.17 \%$ \\
\hline No Overtaking & & 6 & $47.92 \%$ \\
\hline Keep Left & & 5 & $35.78 \%$ \\
\hline TOTAL & & 69 & $40.14 \%$ \\
\hline
\end{tabular}

276 Table 2:

277 Fixation frequency for temporary and ordinary road signs along the work zones considered in 278 the study. 


\begin{tabular}{|c|c|c|c|}
\hline Sign classification & Sign typology & $\#$ & Fixation frequency \\
\hline \multirow{3}{*}{$\begin{array}{c}\text { Temporary Signs } \\
\text { (Yellow Background) }\end{array}$} & Warning & 36 & \multirow{3}{*}{$40.37 \%$} \\
\hline & Direction & 6 & \\
\hline & Warning & 2 & \\
\hline $\begin{array}{c}\text { Ordinary Signs } \\
\text { (White Background) }\end{array}$ & Regulatory & 25 & $39.78 \%$ \\
\hline
\end{tabular}

279

280

The overall mean fixation percentage, weighted according to the frequency of each sign, was $40.14 \%$ (SD: $17.09 \%)$.

The distinction between temporary and permanent signs was not critical for fixation frequency: (mean value $40.37 \%$ and standard deviation 18.51 for temporary signs; mean value $39.78 \%$ and standard deviation 14.11 for permanent signs) (Table 2).

Fixations on work zone signs were not influenced by age $(r=0.07$, n.s. $)$ or gender $(F(1,131)=$ 0.282 , n.s.). Two linear regression models tested the effects of kilometres per year and years of driving experience on the fixation percentage to the road signs included in the work zones. Both regressions were not significant ( $p=0.58$ and $p=0.37$ respectively).

Road sign positioning on approach to the work zones was also considered. Specifically, we compared fixation frequency to the first work zone sign and the following road signs. The fixation frequency was higher for the first sign (M: 41.74\%, $S D$ : 11.80), than for the following road signs (M: 38.94\%, SD: 17.87).

Fixation rate to the first temporary sign in the work zone was compared considering the presence-absence of visible roadwork activity. For work zones with visible activity, the fixation rate to the first temporary sign in the work zone increased to $62.96 \%$ (SD: 33.95). Chi-square test was used and resulted equal to 5.7273 with a p-value of 0.0167 .

\subsection{Fixation duration}

The distribution of fixation durations to the road signs is shown in Figure 3 . Since the distribution was not normal we report the median as a measure of centrality. The median fixation length was of $132 \mathrm{~ms}$ (SD: 108.67, mode: 66 ). The distribution resulted to be highly asymmetrical and positively skewed, with a kurtosis of 14.08 (SD: 0.052) and an asymmetry of 3.06 (SD: 0.027 ). Both Kolmogorov-Smirnov and Shapiro-Wilk normality tests were significant $(p<.001)$, showing that the distribution was not normal.

The average fixation time was also specifically computed considering users' self-evaluation of their driving skills. This was $107.25 \mathrm{~ms}$ (SD: 31.60) for the drivers who self-evaluated their 
driving skills as "average", 169.32 ms (SD: 104.34) for those professing "good" skills and $156.75 \mathrm{~ms}$ (SD: 45.34) for those who thought that they had "excellent" driving skills.

At last, results show that the fixation duration was not influenced by drivers' age, gender or prior experience with the experimental route.

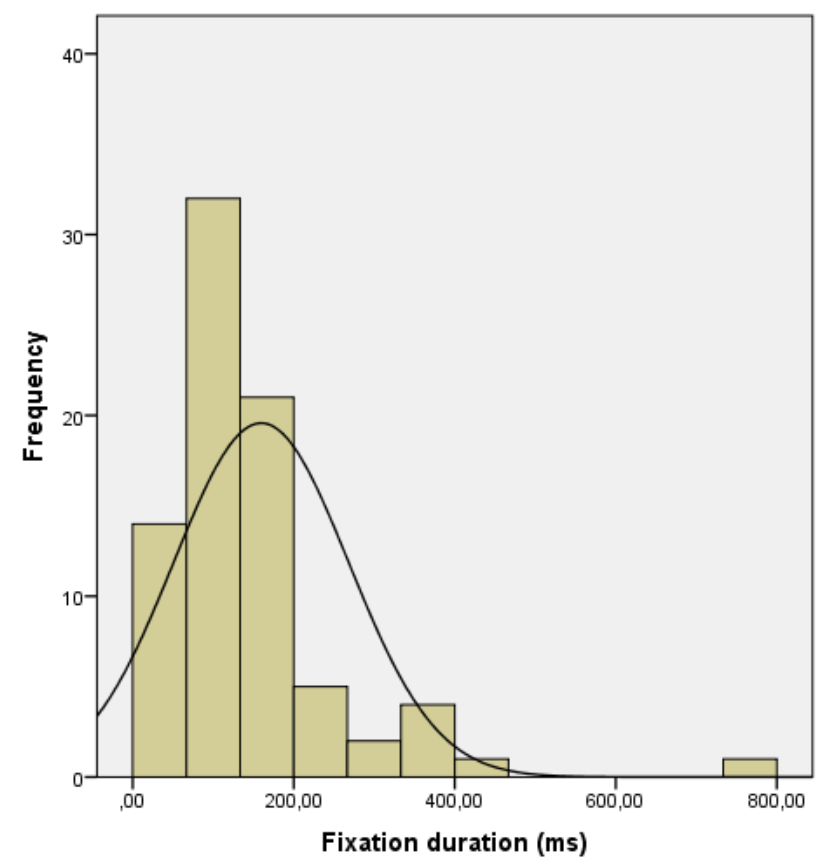

Figure 3: Distribution of fixation duration to the road signs included in the study.

\subsection{Fixation distance}

Results revealed that first-fixation to work zones were generally recorded at a mean distance of $43.5 \mathrm{~m}$ (SD: 32.5 , range $15-80)$, increasing to $48.48 \mathrm{~m}(S D: 34.85)$ if ongoing activity was present. The difference in first-fixation distances with or without ongoing visible activity was not significant. In addition, the ANOVA test for assessing the effects of visible activity as an independent variable on first-fixation distance resulted as non-significant $F(2,74)=2.257$. Also, the mean distance of first fixation was not significantly different considering work zones with one road signs versus work zones with multiple road signs.

\subsection{Speed}

In average, drivers fixated the first sign at each work zone at an instant speed of $55.34 \mathrm{~km} / \mathrm{h}$ (SD: 13.92). Speed limit $(70 \mathrm{~km} / \mathrm{h})$ was exceeded by $14 \%$ of the participants.

The correlation between instant speed and distance of first fixation was equal to $r=0.22$, $p=0.049$. If work zones are distinguished by visible activity, none relevant relationship with sight distance is obtained (Figure 4). 


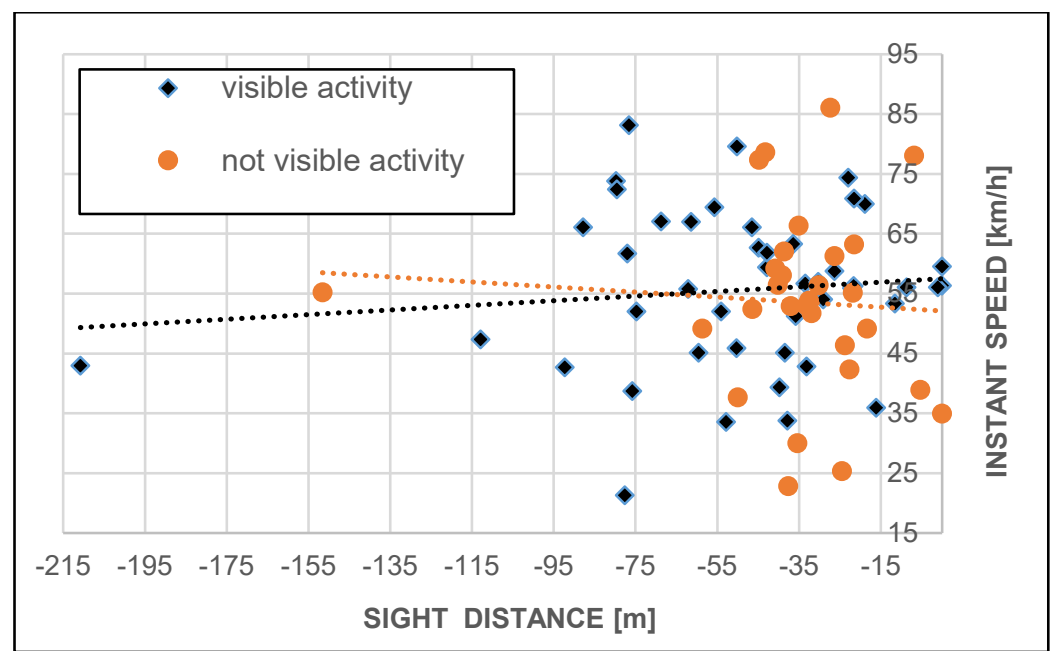

Figure 4. The distribution of first gaze distance/speed, by visible activity.

To determine whether the first fixations occurred at an instant speed that allowed a safe stop of the vehicle in the case of an unexpected obstacle, the distance of first-fixation was compared to the stopping distance. The latter is dependent on travelling speed and has been evaluated as the sum of the reaction distance (reaction time*initial speed) and braking distance, according to Italian regulations (Ministero delle Infrastrutture e dei Trasporti, 2001; World Road Association, 2003). The results showed that distance of first-fixation exceed stopping distance only in $19.48 \%$ of cases.

The other speed parameters were:

- average approaching speed: $55.69 \mathrm{~km} / \mathrm{h}$ (SD: 14.04);

- average speed reduction: $-21.89 \mathrm{~km} / \mathrm{h}(S D: 26.85)$;

- average whole work zone speed:52.21 km/h (SD: 12.18). In terms of driving performance, the linear regression between approaching speed and speed reduction after the first fixation in the work zone was non-significant (Figure 5). To the contrary, the linear regression between approaching speed and the whole work zone average speed was significant $\left(R^{2}=0.55\right.$ and $p=0.05$ in Figure 6$)$. 


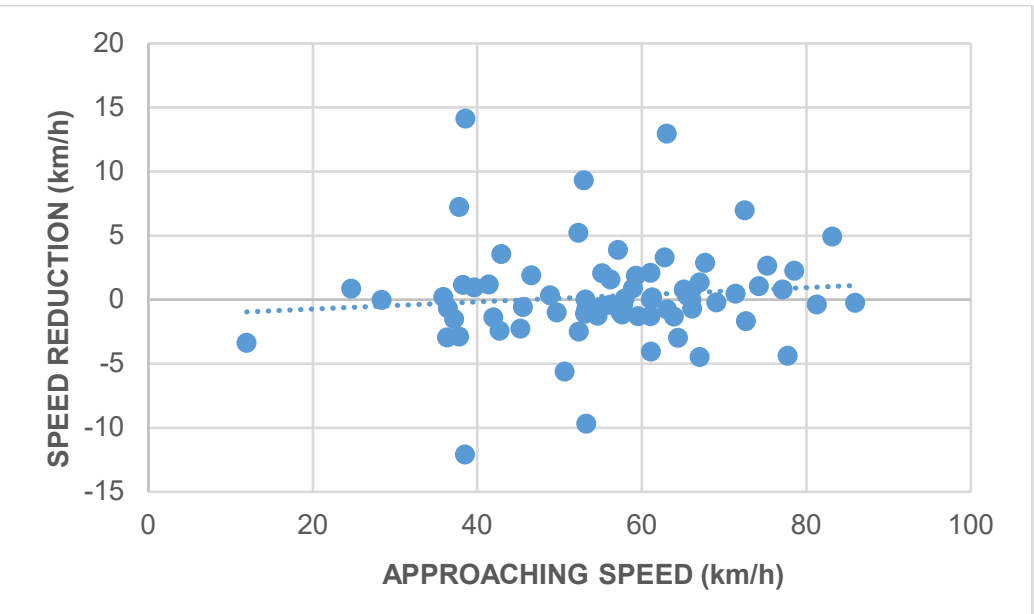

Figure 5: Relationship between approaching speed and speed reduction.

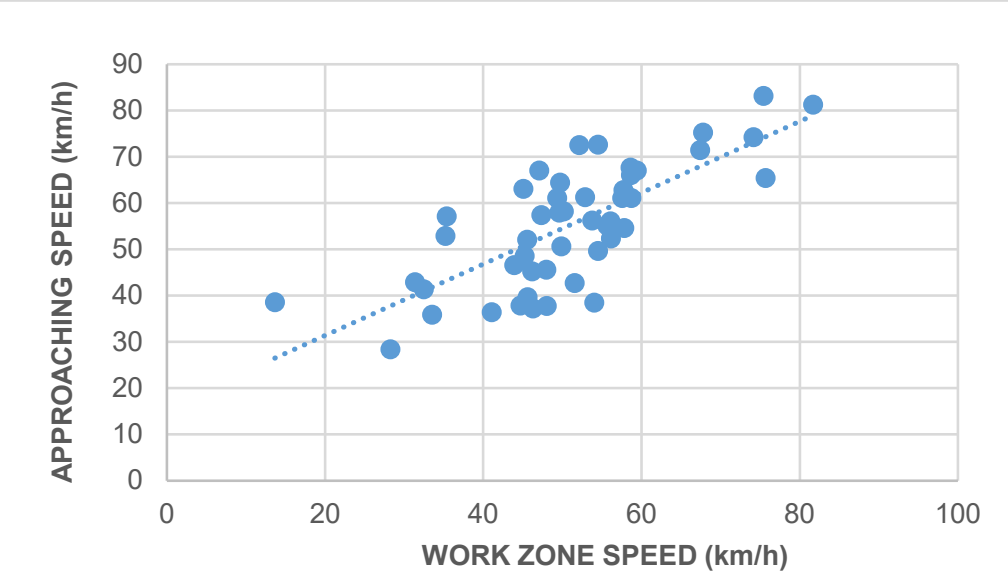

Figure 6: Relationship between work zone speed and approaching speed.

Speed reduction was significantly related to the driver's age $(r=0.35, p<0.001)$ and driving expertise $(r=0.340, p<0.001)$. The work zone average speed results to be related to the drivers' driving expertise $(r=-0.249, p=0.043)$.

\section{DISCUSSION}

The drivers' visual behaviour revealed that work zone signage received very little attention overall, with a mean $40.14 \%$ probability of looking at roadwork signs. The frequency was similar for permanent and temporary road signs. In a recent previous study by Costa et al. (2014), that used a similar experimental protocol but focused on roads without work zones, vertical signs were generally looked at with a $25 \%$ frequency. This comparison clearly shows that in work zones the frequency of road sign glances was higher than in normal road sections. Assuming, however, that the work zone sign primary role is to trigger drivers' attention on modified road setting, the signs failed to be glanced on average in $60 \%$ of the cases, which is very high. This data is even more significant when considering that the participants wore an 
eye tracker device, drove an unfamiliar car and knew that their driving behaviour was being studied. This frequency, however, does not take into account a possible involvement of peripheral vision in road sign detection and identification (Costa, Bonetti, Vignali, Lantieri, \& Simone, 2018).

Gender and age had no influence on fixation frequency, fixation length, fixation distance and speed. For gender, the result confirms previous studies that have monitored eye movements during driving (Costa et al., 2014; Lantieri et al., 2015). The sample, however, was rather low and included only nine females.

Driving expertise had not influence on fixation frequency but correlated significantly with speed reduction approaching the work zone and work zone average speed, coherently with Duncan, Williams, \& Brown, (1991).

About the knowledge of the route, drivers' experience of the route did not have any influencing effect on the fixation frequency. The novelty effect potentially owned by work zone signs has not influenced fixations neither for the drivers who already experienced that road section, nor for unexperienced drivers. To the contrary, experienced drivers had a higher speed crossing the work zones.

About the driving-skill self-evaluation, the drivers who judged their own driving skills as limited drove more carefully exhibiting lower speed. This result is consistent with a study concerning the reliability of drivers' self-reports (West, French, Kemp, \& Elander, 1993). The same category of drivers exhibited also lower fixation times to road signs.

391

\subsection{Work zone features}

Concerning work zone features, it is possible to consider that:

- $\quad$ about the single/multiple temporary signs, isolated single signs in work zones caught more attention by the drivers (in terms of both frequency and average duration of the fixations) than a sequence of signs along a work zone. This could be explained by the height of the signs, as single signs frequently were tripod-mounted and positioned at the bottom of the drivers' visual field (0.6-1.20 $\mathrm{m}$ from the road surface) and are perceived to be narrower, confirming previous studies (Bella, 2009);

- about the ongoing activity on the work zone, ongoing visible activity on the work zone slightly anticipated the distance of first-fixation to the road signs, probably because the presence of dynamic elements on the visual scene increase the conspicuity and

\subsection{Safety considerations}

The present study addressed the importance of understanding the influence of work zone elements on drivers' road sign vision and behaviour. The comparison between average 
approaching speed and average speed reduction revealed a useful test of the efficacy of roadworks signage. Age and poor expertise were predictors for higher speed reductions, but not for fixation rates. Also average whole work zone speed resulted adequate.

The analysis that had a direct implication for road safety is the comparison between the fixation distance and the correspondent stopping distance. The sight distance, whose importance has been extensively discussed in literature (Discetti \& Lamberti, 2011), was frequently lower than stopping distance. Practically, the inadequate effectiveness of signage would not allow a safe stop in case of a sudden obstacle on the road. The knowledge provided would have a strong practical utility for increasing work zone safety levels using appropriate signalling.

In fact, to generalize the presented outcomes, further driving tests should be devised to include diversified road geometries and work zone settings (as length of the advance-warning area, type of first sign, novel instalments as flashing lights, electronic variable message signs and flaggers). On the contrary, authors highlight the importance of maintain the focus of attention on small work zones and consequently on rural environment scenarios, as the risk of severe crashes has been previously proved (Osman et al., 2018).

The reduced sample dimension represents a further limitation of the presented study and certainly will be considered for future testing.

\section{ACKNOWLEDGMENTS}

The research was supported by the Alma Idea 2017 Costa grant from the University of Bologna.

\section{REFERENCES}

AASHTO - American Association of State Highway and Transportation. (2010). Highway Safety Manual (2010th ed.). Washington, D.C.

Beijer, D., Smiley, A., \& Eizenman, M. (2004). Observed Driver Glance Behavior at Roadside Advertising Signs. Transportation Research Record: Journal of the Transportation Research Board, 1899, 96-103. https://doi.org/10.3141/1899-13

Bella, F. (2009). Effects on driver behaviour of different signalling schemes of work zones. Advances in Transportation Studies, 18, 55-68.

Benekohal, R., \& Wang, L. (1994). Relationship between initial speed and speed inside a highway work zone. Transportation Research Record, 1442, 41-48.

Blackman, R. A., Debnath, A. K., \& Haworth, N. L. (2014a). Influence of visible work activity on drivers' speed choice at roadworks. In Proceedings of the 2nd Occupational Safety in Transport Conference, CARRS-Q, Queensland University of Technology, 1-10.

Blackman, R. A., Debnath, A. K., \& Haworth, N. L. (2014b). Work zone items influencing driver speeds at roadworks: worker, driver and expert perspectives. In Australasian 
Road Safety Research, Policing and Education Conference (RSRPE 2014), 12-14 November 2014, Melbourne, Victoria.

Bucchi, A., Sangiorgi, C., \& Vignali, V. (2012). Traffic Psychology and Driver Behavior. Procedia - Social and Behavioral Sciences, 53, 972-979. https://doi.org/10.1016/j.sbspro.2012.09.946

Campbell, J. L., Lichty, M. G., Brown, J. L., Richard M., C., Graving, J. S., Graham, J., O'Laughlin, M., Torbic, D., \& Harwood, D. (2012). NCHRP Report 600: Human Factors Guidelines for Road Systems, Second Edition (Second). Washington, D.C.: Transportation Research Board. Retrieved from http://onlinepubs.trb.org/onlinepubs/nchrp/nchrp_rpt_600Second.pdf

Charlton, S. G. (2006). Conspicuity, memorability, comprehension, and priming in road hazard warning signs. Accident Analysis and Prevention, 38(3), 496-506. https://doi.org/10.1016/j.aap.2005.11.007

Costa, M., Bonetti, L., Vignali, V., Lantieri, C., \& Simone, A. (2018). The role of peripheral vision in vertical road sign identification and discrimination. Ergonomics.

https://doi.org/10.1080/00140139.2018.1508756

Costa, M., Simone, A., Vignali, V., Lantieri, C., Bucchi, A., \& Dondi, G. (2014). Looking behavior for vertical road signs. Transportation Research Part F: Traffic Psychology and Behaviour, 23, 147-155. https://doi.org/10.1016/j.trf.2014.01.003

Costa, M., Simone, A., Vignali, V., Lantieri, C., \& Palena, N. (2018). Fixation distance and fixation duration to vertical road signs. Applied Ergonomics, 69, 48-57. https://doi.org/10.1016/j.apergo.2017.12.017

Crundall, D., \& Underwood, G. (2001). The priming function of road signs. Transportation Research Part F: Traffic Psychology and Behaviour, 4(3), 187-200. https://doi.org/10.1016/S1369-8478(01)00023-7

De Ceunynck, T., Ariën, C., Brijs, K., Brijs, T., Van Vlierden, K., Kuppens, J., Van Der Linden, M., \& Wets, G. (2015). Proactive Evaluation of Traffic Signs Using a Traffic Sign Simulator. European Journal of Transport and Infrastructure Research (EJTIR), 15(2), 184-204.

Discetti, P., \& Lamberti, R. (2011). Traffic Sign Sight Distance for Low-Volume Roads. Transportation Research Record: Journal of the Transportation Research Board, 2203, 64-70. https://doi.org/10.3141/2203-08

Dondi, G., Simone, A., Lantieri, C., \& Vignali, V. (2011). Bike lane design: The context sensitive approach. Procedia Engineering, 21, 897-906. https://doi.org/10.1016/j.proeng.2011.11.2092

Duncan, J., Williams, P., \& Brown, I. (1991). Components of driving skill: experience does not mean expertise. Ergonomics, 34(7), 919-937. 
482

483

484

485

486

487

488

489

490

491

492

493

494

495

496

497

498

499

500

501

502

503

504

505

506

507

508

509

510

511

512

513

514

515

516

517

518

Edquist, J., Horberry, T., Hosking, S., \& Johnston, I. (2011). Effects of advertising billboards during simulated driving. Applied Ergonomics, 42(4), 619-626. https://doi.org/10.1016/j.apergo.2010.08.013

Filtness, A. J., Larue, G., Schramm, A., Fuller, J., Rakotonirainy, A., Han, C., \& Cairney, P. (2017). Safety implications of co-locating road signs: A driving simulator investigation. Transportation Research Part F: Traffic Psychology and Behaviour, 47, 187-198. https://doi.org/10.1016/j.trf.2017.04.007

Finley, M. D., Jenkins, J., \& McAvoy, D. S. (2015). Motorists' Speed Response to Nonvariable and Variable Work Zone Speed Limits and Other Work Zone Conditions. Transportation Research Record: Journal of the Transportation Research Board, 2485, 70-77. https://doi.org/10.3141/2485-09

Fisher, J. (1992). Testing the Effect of Road Traffic Signs' Informational Value on Driver Behavior. Human Factors, 34(2), 231-237. https://doi.org/10.1177/001872089203400208

Gross, F., Persaud, B., \& Lyon, C. (2010). A Guide to Developing Quality Crash Modification Factors. Report No. FHWA-SA-10-032. Washington, DC.

Haworth, N., Symmons, M., \& Mulvhill, C. (2002). Safety of Small Workgroups on Roadways. Victoria, Australia.

Holmqvist, K., Nyström, M., Andersson, R., Dewhurst, R., Jarodzka, H., \& Weijer, J. Van De. (2011). Eye Tracking: A comprehensive guide to methods and measures. Oxford: Oxford University Press.

Khattak, A. J., Khattak, A. J., \& Council, F. M. (2002). Effects of work zone presence on injury and non-injury crashes. Accident Analysis and Prevention, 34(1), 19-29. https://doi.org/10.1016/S0001-4575(00)00099-3

Kröyer, H. R. G., Jonsson, T., \& Várhelyi, A. (2014). Relative fatality risk curve to describe the effect of change in the impact speed on fatality risk of pedestrians struck by a motor vehicle. Accident Analysis and Prevention, 62, 143-152. https://doi.org/10.1016/j.aap.2013.09.007

La Torre, F., Domenichini, L., \& Nocentini, A. (2017). Effects of stationary work zones on motorway crashes. Safety Science, 92, 148-159. https://doi.org/10.1016/j.ssci.2016.10.008

Lantieri, C., Lamperti, R., Simone, A., Costa, M., Vignali, V., Sangiorgi, C., \& Dondi, G. (2015). Gateway design assessment in the transition from high to low speed areas. Transportation Research Part F: Traffic Psychology and Behaviour, 34, 41-53. https://doi.org/10.1016/j.trf.2015.07.017

Lewis, R. M. (1989). Work-Zone Traffic Control Concepts and Terminology. Transportation Research Record, 1230, 1-11. 
Liu, Y. C. (2005). A simulated study on the effects of information volume on traffic signs, viewing strategies and sign familiarity upon driver's visual search performance. International Journal of Industrial Ergonomics, 35(12), 1147-1158. https://doi.org/10.1016/j.ergon.2005.06.009

Mantuano, A., Bernardi, S., \& Rupi, F. (2017). Cyclist gaze behavior in urban space: An eyetracking experiment on the bicycle network of Bologna. Case Studies on Transport Policy, 5(2), 408-416. https://doi.org/10.1016/j.cstp.2016.06.001

Ministero delle Infrastrutture e dei Trasporti (2001). Norme Funzionali Geometriche per la Costruzione delle Strade.

Osman, M., Paleti, R., \& Mishra, S. (2018). Analysis of passenger-car crash injury severity in different work zone configurations. Accident Analysis and Prevention, 111(2018), 161172. https://doi.org/10.1016/j.aap.2017.11.026

Rahman, M. M., Strawderman, L., Garrison, T., Eakin, D., \& Williams, C. C. (2017). Work zone sign design for increased driver compliance and worker safety. Accident Analysis and Prevention, 106, 67-75. https://doi.org/10.1016/j.aap.2017.05.023

Steinbakk, R. T., Ulleberg, P., Sagberg, F., \& Fostervold, K. I. (2017). Analysing the influence of visible roadwork activity on drivers' speed choice at work zones using a video-based experiment. Transportation Research Part F: Traffic Psychology and Behaviour, 44, 5362. https://doi.org/10.1016/j.trf.2016.10.003

Summala, H., \& Hietamaki, J. (1984). Drivers' immediate responses to traffic signs. Ergonomics, 27(2), 205-216. https://doi.org/10.1080/00140138408963478

Taylor, T., Pradhan, A. K., Divekar, G., Romoser, M., Muttart, J., Gomez, R., Pollatsek, A., \& Fisher, D. L. (2013). The view from the road: The contribution of on-road glancemonitoring technologies to understanding driver behavior. Accident Analysis and Prevention, 58, 175-186. https://doi.org/10.1016/j.aap.2013.02.008

Topolšek, D., Areh, I., \& Cvahte, T. (2016). Examination of driver detection of roadside traffic signs and advertisements using eye tracking. Transportation Research Part F: Traffic Psychology and Behaviour, 43, 212-224. https://doi.org/10.1016/j.trf.2016.10.002

Ullman, B. R., Trout, N. D., \& Dudek, C. L. (2009). Use of Graphics and Symbols on Dynamic Message Signs: Technical Report, 7(2).

Ullman, G., \& Brewer, M. (2014). Driver Perceptions of Traffic-Calming Versus Active Enforcement Efforts in Work Zones. Transportation Research Record: Journal of the Transportation Research Board, 2425, 25-31. https://doi.org/10.3141/2425-04

Vienna Convention. (1968). Protocol on road signs and signals. In Journal of chromatographic science,51. https://doi.org/10.1093/chromsci/bms220

West, R., French, D., Kemp, R., \& Elander, J. (1993). Direct observation of driving, self reports of driver behaviour, and accident involvement. Ergonomics, 36(5), 557-567. 
https://doi.org/10.1080/00140139308967912

557 World Road Association (PIARC), 2003. Road safety manual.

558 Yang, H., Ozturk, O., Ozbay, K., \& Xie, K. (2015). Work zone safety analysis and modeling: a 559 state-of-the-art review. Traffic Injury Prevention, 16(4), 387-396.

$560 \quad$ https://doi.org/https://doi.org/10.1080/15389588.2014.948615

561 Zwahlen, H. T. (1995). Traffic sign reading distances and times during night driving.

562 Transportation Research Record, 1495, 140-146.

563 